\title{
Is there a role for targeted medical therapies in patients with craniopharyngiomas?
}

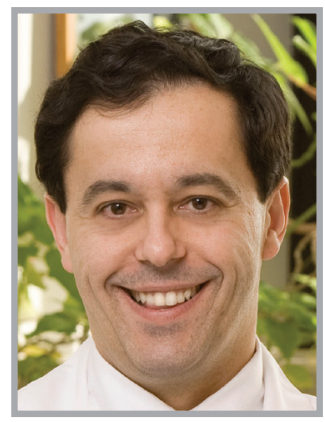

Nicholas A Tritos*
"Our understanding of the molecular mechanisms underlying papillary craniopharyngiomas has been advanced as a result of recent observations implicating somatic BRAF gene mutations in the pathogenesis of these uncommon, yet potentially devastating, tumors."
Is there a role for medical therapy in patients with craniopharyngiomas?

Craniopharyngiomas are uncommon tumors that arise from remnants of the epithelium of the craniopharyngeal (Rathke's) pouch [1]. Worldwide, the incidence of craniopharyngiomas has been estimated to be 1.34 cases per million population per year [2]. These tumors follow a bimodal age distribution, peaking in incidence during childhood (ages 5-14 years) and again in the fourth to sixth decades of life [2]. Although they are generally benign on histologic examination, these tumors are locally adherent to surrounding brain tissue and often impinge on critical suprasellar and sellar structures, causing mass effect (optic neuropathy, hydrocephalus), neurobehavioral, neurocognitive and neuroendocrine deficits (anterior hypopituitarism, diabetes insipidus, hypothalamic dysfunction, obesity), thus leading to substantial short-term and long-term morbidity [3].

It has been long recognized that surgical resection of craniopharyngiomas (performed either transcranially or transsphenoidally) can be technically challenging, not only because of their central location within the cranium but also because of their adherence to critical structures. Not surprisingly, Harvey Cushing referred to craniopharyngiomas as "the most forbidding of the intracranial tumors" [4]. To minimize neurologic and neuroendocrine sequel associated with surgery, neurosurgeons often have to settle for subtotal tumor resection and treat residual (or recurrent) disease with radiation therapy [1]. Despite advances in neurosurgery and radiation therapy, patients with craniopharyngiomas may often experience substantial long-term morbidity associated with their underlying condition or related therapies, including neurocognitive deficits, vision loss, hypopituitarism, obesity and the metabolic syndrome occurring as a result of hypothalamic damage $[5,6]$. Such long-term sequelae likely account for the frequent occurrence of impairments in vocational and social function and poor quality of life in this patient group [7]. In addition, excess long-term mortality has been reported in patients with treated craniopharyngiomas, ranging between three- and five-times that in the general population $[3,6]$. Clearly,

\section{KEYWORDS}

- adamantinomatous

craniopharyngioma $\bullet B R A F$

- dabrafenib - papillary

craniopharyngioma $\bullet$ vemurafenib 


\section{"Craniopharyngiomas come in two histologic types, including adamantinomatous tumors, which are overall more common and are more frequently seen in children and adolescents, and papillary tumors, which are almost exclusively seen in older adults."}

there are significant unmet medical needs that are very relevant to the care of these patients.

Until recently, the pathogenesis of craniopharyngiomas had been ill understood. However, recent data have shed new light in the molecular underpinnings of these tumors. Craniopharyngiomas come in two histologic types, including adamantinomatous tumors, which are overall more common and are more frequently seen in children and adolescents, and papillary tumors, which are almost exclusively seen in older adults [1]. Observations made in several studies published since the turn of the millennium suggested that somatic mutations of the gene encoding beta catenin (CTNNB1) are frequent in patients with adamantinomatous craniopharyngiomas (occurring in up to $100 \%$ of tumors examined in some studies) [8-10]. These data implicate the Wnt signaling pathway in the pathogenesis of adamantinomatous craniopharyngiomas.

More recently, a group of investigators identified the presence of a somatic, clonal $B R A F$ gene mutation (V600E) in all three specimens obtained from papillary craniopharyngiomas using whole-exome sequencing [11]. Targeted genotyping subsequently confirmed the presence of this $B R A F$ gene mutation in $95 \%$ of craniopharyngiomas (36 out of 39 tumors examined). Furthermore, this mutation was not present in any of the tumor specimens from adamantinomatous craniopharyngiomas, 92-96\% of which had a CTNNB1 gene mutation [11]. In a study from another group, the presence of the same (V600E) BRAF gene mutation was reported in $81 \%$ of papillary craniopharyngiomas (17 out of 21 tumors) examined by targeted Sanger sequencing [12]. In addition, two out of 16 adamantinomatous craniopharyngiomas with a CTNNB1 gene mutation had this BRAF gene mutation. These findings suggest that $B R A F$ and CTNNB1 gene mutations are not mutually exclusive in these tumors, but nevertheless tend to occur predominantly in papillary and adamantinomatous craniopharyngiomas, respectively.

The V600E BRAF gene mutation leads to constitutive activation of the B-Raf protein, a 766 amino acid member of the Raf kinase family, which functions as a serine/threonine specific protein kinase and transduces cell proliferative signals mediated through the MAPK kinase (MEK) pathway [13]. Furthermore, the same somatic $B R A F$ gene mutation has been frequently reported in a variety of tumors, including malignant melanoma, non-small-cell lung cancer, colorectal cancer, papillary thyroid carcinoma and hairy cell leukemia [13]. Based on observations suggesting that $B R A F$ gene mutations drive tumor cell proliferation, it would be anticipated that B-Raf inhibition would likely be efficacious in patients whose tumors harbor specific activating $B R A F$ gene mutations.

Several B-Raf inhibitors have been developed, including vemurafenib, dabrafenib and sorafenib (the last one being an inhibitor of B-Raf and C-Raf). Administration of the B-Raf inhibitor vemurafenib, which selectively inhibits the catalytically active conformation of B-Raf, was shown to prolong survival in patients with metastatic melanomas whose tumors are positive for the V600E BRAF gene mutation [14,15]. More recently, the co-administration of dabrafenib together with trametinib (a MEK inhibitor) was associated with a significantly lower risk of death (relative risk: 0.69 ) in patients with metastatic melanoma positive for a $B R A F$ gene mutation (V600E or V600K) in comparison with patients assigned to vemurafenib alone [16].

These encouraging findings suggested that B-Raf inhibition might also be efficacious in patients with papillary craniopharyngiomas. A recent publication reported on the case of a patient with papillary craniopharyngioma and vision loss, whose tumor was refractory to three transsphenoidal resections and radiation therapy [17]. After the tumor was confirmed to harbor the $\mathrm{V} 600 \mathrm{E} B R A F$ gene mutation, the patient was treated with vemurafenib [17]. In response to this therapy, there was prompt decrease in tumor size leading to improvement in vision. The tumor response was reversed upon drug discontinuation [17]. Subsequently, there was evidence of tumor response noted upon reinstitution of vemurafenib therapy. These observations are consistent with the hypothesis that $B R A F$ gene mutations are of pathogenic significance ('driver mutations') in patients with papillary craniopharyngiomas and serve as a 'proof of principle', suggesting that B-Raf inhibition might be a viable therapeutic strategy in patients with these tumors.

Although the report of a papillary craniopharyngioma responding to vemurafenib therapy appears to be promising, there are many questions that remain unanswered. Will tumor responses occur consistently in larger numbers of patients with papillary craniopharyngiomas? Will such tumor responses be durable? Might 
B-Raf inhibition be effective as neoadjuvant therapy to improve the extent of surgical resection? What is the role of B-Raf inhibition as adjuvant therapy in patients with residual tumor after surgery in comparison with that of radiation therapy? Larger studies will obviously be needed to address these issues.

Our understanding of the molecular mechanisms underlying papillary craniopharyngiomas has been advanced as a result of recent observations implicating somatic $B R A F$ gene mutations in the pathogenesis of these uncommon, yet potentially devastating, tumors. In addition, these findings appear to open new avenues in the diagnosis and management of these tumors, including the potential use of the V600E $B R A F$ gene mutation as a diagnostic marker in patients with suspected papillary craniopharyngiomas and the possible use of B-Raf inhibitors as targeted therapies. It can only be hoped that similar progress will soon be made in the diagnosis and management of other, more common pituitary mass lesions, including pituitary adenomas.

\section{Financial \& competing interests disclosure}

The author has no relevant affiliations or financial involvement with any organization or entity with a financial interest in or financial conflict with the subject matter or materials discussed in the manuscript. This includes employment, consultancies, honoraria, stock ownership or options, expert testimony, grants or patents received or pending, or royalties.

No writing assistance was utilized in the production of this manuscript.

\section{References}

1 Karavitaki N, Cudlip S, Adams CB, Wass JA. Craniopharyngiomas. Endocr. Rev. 27(4), 371-397 (2006).

2 Nielsen EH, Feldt-Rasmussen U, Poulsgaard $\mathrm{L}$ et al. Incidence of craniopharyngioma in Denmark $(n=189)$ and estimated world incidence of craniopharyngioma in children and adults. J. Neurooncol. 104(3), 755-763 (2011).

3 Pereira AM, Schmid EM, Schutte PJ et al. High prevalence of long-term cardiovascular, neurological and psychosocial morbidity after treatment for craniopharyngioma. Clin. Endocrinol. (Oxf.) 62(2), 197-204 (2005).

4 Cushing H. Intracranial Tumors. Notes Upon a Series of Two Thousand Cases With Surgical Mortality Percentages Pertaining Thereto. Thomas, Springfield, IL (1932).

5 Gautier A, Godbout A, Grosheny C et al. Markers of recurrence and long-term morbidity in craniopharyngioma: a systematic analysis of 171 patients. J. Clin. Endocrinol. Metab. 97(4), 1258-1267 (2012).

6 Olsson DS, Andersson E, Bryngelsson IL, Nilsson AG, Johannsson G. Excess mortality and morbidity in patients with craniopharyngioma, especially in patients with childhood onset: a population-based study in Sweden. J. Clin. Endocrinol. Metab. 100(2), 467-474 (2015).

7 Dekkers OM, Biermasz NR, Smit JW et al. Quality of life in treated adult craniopharyngioma patients. Eur. J. Endocrinol. 154(3), 483-489 (2006).

8 Buslei R, Nolde M, Hofmann B et al. Common mutations of beta-catenin in adamantinomatous craniopharyngiomas but not in other tumours originating from the sellar region. Acta Neuropathol. 109(6), 589-597 (2005).

9 Oikonomou E, Barreto DC, Soares B, De Marco L, Buchfelder M, Adams EF. Beta-catenin mutations in craniopharyngiomas and pituitary adenomas. J. Neurooncol. 73(3), 205-209 (2005).

10 Sekine S, Shibata T, Kokubu A et al. Craniopharyngiomas of adamantinomatous type harbor beta-catenin gene mutations. $A m$. J. Pathol. 161(6), 1997-2001 (2002).

11 Brastianos PK, Taylor-Weiner A, Manley PE et al. Exome sequencing identifies $B R A F$ mutations in papillary craniopharyngiomas. Nat. Genet. 46(2), 161-165 (2014).
12 Larkin SJ, Preda V, Karavitaki N, Grossman A, Ansorge O. BRAF V600E mutations are characteristic for papillary craniopharyngioma and may coexist with CTNNB1-mutated adamantinomatous craniopharyngioma. Acta Neuropathol. 127(6), 927-929 (2014).

13 Davies H, Bignell GR, Cox C et al. Mutations of the $B R A F$ gene in human cancer. Nature 417(6892), 949-954 (2002).

14 Chapman PB, Hauschild A, Robert C et al. Improved survival with vemurafenib in melanoma with BRAF V600E mutation. N. Engl. J. Med. 364(26), 2507-2516 (2011).

15 Sosman JA, Kim KB, Schuchter L et al. Survival in BRAFV600-mutant advanced melanoma treated with vemurafenib. $N$. Engl. J. Med. 366(8), 707-714 (2012).

16 Robert C, Karaszewska B, Schachter J et al. Improved overall survival in melanoma with combined dabrafenib and trametinib. N. Engl. J. Med. 372(1), 30-39 (2015).

17 Aylwin SJ, Bodi I, Beaney R. Pronounced response of papillary craniopharyngioma to treatment with vemurafenib, a BRAF inhibitor. Pituitary doi:10.1007/s11102-0150663-4 (2015) (Epub ahead of print). 